\title{
Decision Rules Guiding the Clinical Diagnosis of Alzheimer's Disease in Two Community-Based Cohort Studies Compared to Standard Practice in a Clinic-Based Cohort Study
}

\author{
David A. Bennett ${ }^{a, b}$ Julie A. Schneider ${ }^{a-c}$ Neelum T. Aggarwal ${ }^{a, b}$ \\ Zoe Arvanitakisa,b Raj C. Shah ${ }^{a, e}$ Jeremiah F. Kelly ${ }^{a, f}$ Jacob H. Fox ${ }^{b}$ \\ Elizabeth J. Cochran ${ }^{c}$ Danielle Arends ${ }^{a}$ Anna D. Treinkman ${ }^{a}$ \\ Robert S. Wilson ${ }^{\mathrm{a}, \mathrm{b}, \mathrm{d}}$ \\ ${ }^{a}$ Rush Alzheimer's Disease Center and Departments of b Neurological Sciences, ${ }^{\text {CPathology, }}{ }^{\mathrm{d}}$ Behavioral Sciences, \\ eFamily Practice and f Internal Medicine, Rush University Medical Center, Chicago, III., USA
}

\section{Key Words}

Alzheimer's disease · Alzheimer's disease, diagnosis •

Decision rules · Alzheimer's disease, pathology

\begin{abstract}
We developed prediction rules to guide the clinical diagnosis of Alzheimer's disease (AD) in two community-based cohort studies (the Religious Orders Study and the Rush Memory and Aging Project). The rules were implemented without informant interviews, neuroimaging, blood work or routine case conferencing. Autopsies were performed at death and the pathologic diagnosis of AD made with a modified version of the Consortium to Establish a Registry for Alzheimer's Disease (CERAD) criteria. We compared the positive predictive value of the clinical diagnosis in the two communitybased studies to the positive predictive value of the clinical diagnosis of AD made by standard clinical practice in a clinicbased cohort study using AD pathology as the gold standard. Of 306 clinic cases with probable AD, 286 (93.5\%) met CERAD neuropathologic criteria for $A D$; the results were comparable for those with possible AD (51 of 54, 94.4\%). Of 141 study subjects with probable AD, 130 (92.2\%) met CERAD
\end{abstract}

neuropathologic criteria for $A D$; the results were lower but acceptable for those with possible AD (26 of 37, 70.3\%). The results were similar in secondary analyses using alternate neuropathologic criteria for AD. The clinical diagnosis of AD can be made in community-based studies without the use of informant interviews, neuroimaging, blood work or routine case conferencing. This approach holds promise for reducing the operational costs of epidemiologic studies of aging and $A D$.

Copyright $\odot 2006$ S. Karger AG, Basel

\section{Introduction}

Epidemiologic studies of risk factors for incident Alzheimer's disease (AD) depend on correct diagnostic classification of disease status. However, the clinical diagnosis of AD in community-based studies can be difficult, time-consuming and expensive. We are conducting two community-based studies of risk factors for incident $\mathrm{AD}$ that include organ donation at death: the Religious Orders Study [1] and the Rush Memory and Aging Project $[1,2]$. Evaluations take place across the country and

\section{KARGER}

(C) 2006 S. Karger AG, Basel

Fax +41613061234

E-Mail karger@karger.ch

www.karger.com
Accessible online at: www.karger.com/ned
David A. Bennett, MD

Rush Alzheimer's Disease Center

600 South Paulina, Suite 1028

Chicago, IL 60612 (USA)

Tel.+1 312942 2362,E-Mail dbennett@rush.edu 


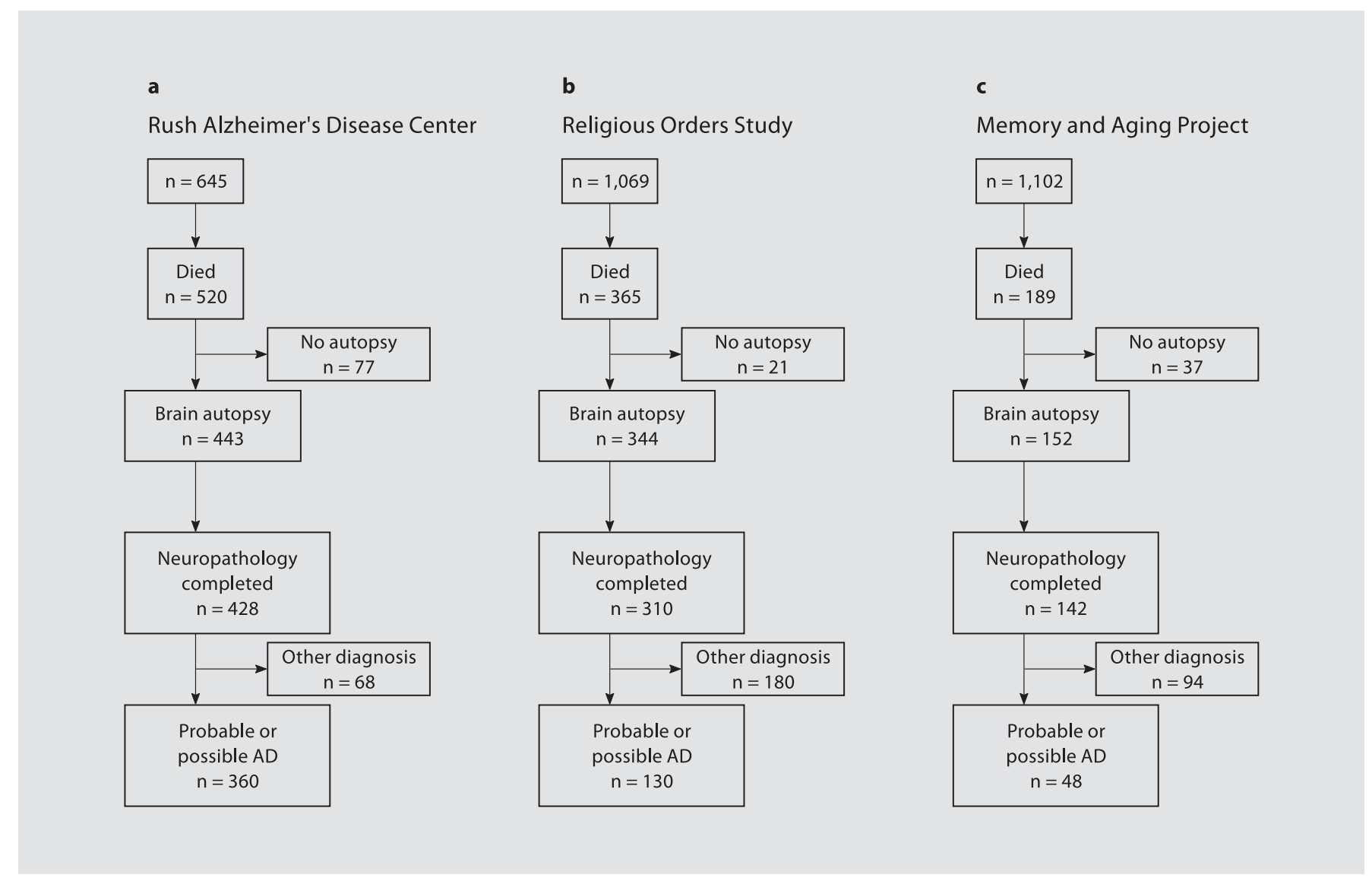

Fig. 1. Flow of subjects, deaths, autopsies and completed neuropathologic evaluations for the clinic-based cohort study (a) and each of the two community studies (b, c).

Northeastern Illinois. We conduct a complete clinical evaluation on all study participants each year to ensure that postmortem indices can be related to clinical data and diagnoses proximate to death. To maintain diagnostic consistency across time, space and examiners, we developed a computer-based system of prediction rules to guide clinical judgment for the diagnosis of $\mathrm{AD}$. It was not operationally feasible or cost-efficient to interview informants, obtain neuroimaging and blood work or perform case conferences for all evaluations. Because in-person evaluations were not always possible, the system permits diagnoses to be made by clinicians based on review of clinical data obtained by trained nurses, neuropsychological test technicians and research assistants. In this report, we examine the relation of the clinical diagnosis of $\mathrm{AD}$ to the pathologic diagnosis of $\mathrm{AD}$ for more than 175 study subjects. The results are compared to the clinical diagnosis of $\mathrm{AD}$ made by standard clinical practice to the pathologic diagnosis of $\mathrm{AD}$ for more than 350 persons evaluated at the Rush Alzheimer's Disease Center. We present the positive predictive value (true positives divided by true and false positives) rather than sensitivity, specificity and diagnostic accuracy because AD pathology is common in persons without dementia [3-7].

\section{Methods}

\section{Study Populations}

Rush Alzheimer's Disease Center Clinic

Participants were persons evaluated for possible dementia at the Rush Alzheimer's Disease Center clinic who agreed to brain autopsy as part of the clinical core of the Rush Alzheimer's Disease Core Center. The study was approved by the Institutional Review Board of the Rush University Medical Center. Following death, next of kin provided consent for autopsy. Of more than 650 persons who underwent clinical evaluation between March 1992 and June 2006, the autopsy rate exceeds $85 \%$ with 443 autopsies of 520 deaths (fig. 1a). 
Religious Orders Study

The participants were older Catholic nuns, priests and brothers without known dementia who agreed to annual clinical evaluations and signed an informed consent and an Anatomical Gift Act donating his/her brain to Rush investigators at the time of death [1]. The study was approved by the Institutional Review Board of the Rush University Medical Center. The subjects come from about 40 groups in 12 states across the country. The study has a rolling admission, and more than 1,000 persons completed a uniform structured baseline clinical evaluation between January 1994 and June 2006. Follow-up evaluations, identical in all essential details, were performed annually by examiners blinded to previously collected data. Participation in the annual follow-up evaluations exceeds $95 \%$ of survivors. The autopsy exceeds $90 \%$ with 344 autopsies of 365 deaths (fig. 1b).

\section{Rush Memory and Aging Project}

The participants were older community-dwelling persons without known dementia who agreed to annual clinical evaluations and signed an informed consent and an Anatomical Gift Act donating his/her brain, spinal cord, and selected nerve and muscle to Rush investigators at the time of death $[1,2]$. The study was approved by the Institutional Review Board of the Rush University Medical Center. The subjects come from about 40 retirement communities and senior housing buildings across Cook and the collar counties in northeastern Illinois. Subjects also are recruited from local churches. The study has a rolling admission, and more than 1,100 persons completed a uniform structured baseline clinical evaluation between October 1997 and June 2006. Follow-up evaluations, identical in all essential details, were performed annually by examiners blinded to previously collected data. Participation in the annual follow-up evaluations exceeds $95 \%$ of survivors. The autopsy rate exceeds $80 \%$ with 152 autopsies of 189 deaths (fig. 1c).

\section{Clinical Procedures}

Rush Alzheimer's Disease Center Clinic

All subjects underwent a uniform, structured, clinical evaluation. Details of the evaluation have been previously reported [810]. Briefly, the evaluation included a detailed medical history with the patient and a knowledgeable informant, neurologic examination, and brief psychiatric evaluation conducted by skilled neurologists, geriatricians and geriatric nurse practitioners. Laboratory testing and structural neuroimaging were performed, and ancillary tests (e.g. examination of cerebrospinal fluid, positron emission tomography) were obtained when clinically indicated. The procedures were compatible with the Consortium to Establish a Registry for Alzheimer's Disease (CERAD) [11], similar to those conducted by clinical cores of other federally funded $\mathrm{AD}$ centers, and consistent with the current practice parameters for the diagnostic evaluation for dementia [12]. Cognitive function was assessed with a battery of 19 neuropsychological tests administered by neuropsychological test technicians. The battery included measures of orientation, attention, memory, language and visual perception widely used in clinical evaluation of older persons with suspected dementia. Detailed psychometric information on the test battery used from 1992 to 1999 is published elsewhere [8]. In 1999, the core battery was changed to be compatible with the cognitive testing being performed in the Religious Orders Study and the Memory and Aging Project (below). Five tests were administered across all 14 years.

Decision Rules Guiding the Clinical

Diagnosis of Alzheimer's Disease
The diagnosis of $\mathrm{AD}$ required a history of cognitive decline and evidence of impairment in memory and other cognitive abilities according to the National Institute of Neurological and Communicative Disorders and Stroke/Alzheimer's Disease and Related Disorders Association (NINDCS/ADRDA) criteria [13]. Cognitive impairment related to stroke was made according to the National Institute of Neurological Disorders and Stroke/Association Internationale pour la Recherche et l'Enseignement en Neurosciences (NINDS/AIREN) criteria for vascular dementia [14], parkinsonism and Parkinson's disease according to the clinical criteria recommended by the Core Assessment Program for Intracerebral Transplantation (CAPIT) [15], and major depression based on DSM-III-R criteria supported by the Hamilton rating scale for depression [16].

Religious Orders Study and Memory and Aging Project

All subjects underwent a uniform, structured, clinical evaluation that included a self-report medical history obtained by trained nurses and research technicians, a neurologic examination by trained nurses and cognitive function testing by trained neuropsychological test technicians. Years of formal education, lifetime and current occupation, and history of change in memory and other cognitive abilities were documented. History of stroke, Parkinson's disease, depression, head trauma and other conditions with the potential to cause cognitive impairment were obtained by structured questionnaire. Depression was assessed with items from the Diagnostic Interview Schedule [17]. All medications used in the prior two weeks were directly inspected and recorded. A complete neurologic examination documented evidence of stroke and Parkinson's disease [18]. A battery of 21 neuropsychological tests was administered and scored by a computer as previously described $[2,19]$. Because participants reside throughout the United States, the battery included a subset of tests that could be administered by telephone [20].

We developed a set of prediction rules to guide clinical classification of AD, incorporating selected clinical judgments at several key decision points. Such rules have been used in many areas of medicine [21-23]. Because the Catholic clergy are without spouses and children, and because of the need to maintain confidentiality in settings in which participants live communally, we did not identify and interview informants. To ensure uniformity of procedures and reduce costs, we did not include neuroimaging and blood laboratory work. Because of the number of clinical evaluations, we did not case conference all evaluations. The decision rules were implemented in a multi-step process [24,25]:

(1) History of cognitive decline was based on a structured interview with the participant as done by others [26]. We previously reported that self-report cognitive decline identified by this interview is related to $\mathrm{AD}$ pathology [27].

(2) We developed cutoff scores for 11 commonly used tests, adjusted them for 4 educational strata and used an algorithm to convert the impairment ratings for the 11 tests into impairment ratings in 5 areas of cognition (orientation, attention, memory, language and visuospatial ability) as previously described (see table 1, p. 199, in Bennett et al. [24]).

(3) A neuropsychologist, without access to subject age, gender and race, reviewed the impairment ratings, the remaining cognitive test results, education, occupation, sensory and motor deficits, effort and comments from the neuropsychological test technician regarding protocol deviation (e.g. participant blind and 
test not administered) and rendered a clinical judgment (i.e. agreed or disagreed with the computer-generated impairment rating) regarding the presence of impairment in each area of cognition. Impairment in 1 or 2 areas was consistent with single- or multiple-domain mild cognitive impairment [28], and impairment in 3-5 areas was consistent with dementia. When 2 areas of impairment were present, the neuropsychologist rendered an opinion regarding the presence of dementia.

(4) A clinician (neurologist, geriatrician or geriatric nurse practitioner) reviewed all available data and examined the participant and entered selected data into a computer, including (a) history of cognitive decline, (b) the neuropsychologist's judgment of the number of impaired domains and the presence of memory impairment and (c) a clinical judgment regarding meaningful cognitive decline. An actuarial decision tree generated a clinical diagnosis of dementia and AD based on NINCDS/ADRDA criteria [13]. The clinician was then offered an opportunity to override the actuarial decision. Similar procedures were used for dementia related to stroke, Parkinson's and Lewy body disease, and depression [14-16]. Other conditions (e.g. frontotemporal dementia) were made by strict clinical judgment.

For all 3 studies, all available clinical data were reviewed at the time of death by a neurologist, and a summary diagnostic opinion was rendered regarding the most likely clinical diagnosis at the time of death. In most cases, the clinical diagnosis was straightforward. Case conferencing with a second neurologist and a neuropsychologist occurred when the diagnosis was not obvious, typically in the presence of a coexisting condition (e.g. stroke, parkinsonism, delirium).

\section{Brain Autopsy Procedures}

Brain autopsies were performed at Rush and 11 predetermined sites across the United States for nearly all cases as described previously $[1,29]$. Following drainage of cerebrospinal fluid, the brains were removed and weighed. The brainstem and cerebellum were removed, and the brain was hemisected. Each hemisphere was placed in a Plexiglas jig and cut coronally into $1-\mathrm{cm}$ slabs. Slabs from one hemisphere were fixed for 3-21 days in $4 \%$ paraformaldehyde, at which time they underwent complete macroscopic evaluation and dissection of diagnostic blocks, including midfrontal, superior temporal, inferior parietal and entorhinal cortex, hippocampus, basal ganglia, thalamus and substantia nigra. These were embedded in paraffin, cut into $6-\mu \mathrm{m}$ sections and mounted on glass slides.

\section{Pathologic Diagnosis of AD}

Bielschowsky silver stain was used to visualize neuritic plaques, diffuse plaques and neurofibrillary tangles in the frontal, temporal, parietal and entorhinal cortex, and the hippocampus. Neuropathologic diagnoses were made by a board-certified neuropathologist without access to any clinical information. A neuropathologic diagnosis was made of 'no AD,' 'possible AD,' 'probable AD' or 'definite AD' based on semiquantitative estimates of neuritic plaque density as recommended by CERAD [30]. To examine the rate of agreement between clinical and pathologic diagnoses, the CERAD neuropathologic diagnosis of AD was modified to be implemented without clinical information (i.e. without adjustment for age and clinical diagnosis), as previously reported $[1,29]$. Braak stages I-VI were based upon the distribution and severity of neurofibrillary tangle pathology [31]. All cases also received a neuropathologic diagnosis of 'no AD,' 'low likelihood AD,' 'intermediate likelihood AD' or 'high likelihood AD' by the National Institute on Aging (NIA)-Reagan criteria [32].

Pathologic Diagnoses of Cerebral Infarcts and Lewy Body Disease

For each brain the age, volume (in $\mathrm{mm}^{3}$ ), side and location of all macroscopic cerebral infarctions were recorded, and microscopic infarcts were also recorded on sections stained with hematoxylin and eosin as previously described [33]. Lewy bodies were identified with antibodies to $\alpha$-synuclein and recorded as nigral predominant, limbic or neocortical type as recommended by the report of the consortium on dementia with Lewy bodies international workshop as previously described [34, 35].

\section{Data Analysis}

Probable AD refers to persons with clinical AD who did not have any other condition contributing to dementia, and possible $\mathrm{AD}$ refers to persons with clinical $\mathrm{AD}$ and another coexisting condition contributing to dementia (e.g. stroke). We computed the positive predictive value, true positives divided by true plus false positives $[\mathrm{TP} /(\mathrm{TP}+\mathrm{FP})]$, of the clinical diagnoses of $\mathrm{AD}$ with the pathologic diagnoses separately for the clinic cases and study subjects. The primary analyses were performed with CERAD neuropathologic diagnosis. NIA-Reagan pathologic diagnosis was provided as another way to examine the postmortem data.

\section{Results}

Of 428 completed clinic autopsies, 306 persons had clinically probable $\mathrm{AD}$ and 54 clinically possible $\mathrm{AD}$ (fig. 1a). Of 452 completed Religious Orders Study and Memory and Aging Project autopsies, 141 persons had clinically probable $\mathrm{AD}$ and 37 clinically possible $\mathrm{AD}$ (fig. $1 b, c)$. The study subjects with probable AD were about 10 years older at death, had about 4 years more education and scored more than 10 points higher on the Mini-Mental State Examination (MMSE) [36]; the study subjects with possible $\mathrm{AD}$ were about 7 years older at death, had about 3 years more education and scored about 8 points higher on the MMSE (table 1 ).

\section{Relation of Clinical Diagnoses of AD to Pathologic Diagnoses in Clinic Cases}

Of 306 clinic cases with clinically probable AD, 286 (93.5\%) met CERAD pathologic criteria for definite or probable AD (table 2). Similarly, more than $90 \%$ met NIAReagan criteria for intermediate or high likelihood of pathologic AD. In addition, nearly $15 \%$ had 1 or more chronic macroscopic cerebral infarctions, and nearly a quarter had nigral, limbic or neocortical Lewy bodies. Of 54 clinic cases with clinically possible AD, 51 (94.4\%) met CERAD pathologic criteria for definite or probable AD 
Table 1. Demographic characteristics of autopsied patients with probable AD and possible AD from the Rush Alzheimer's Disease Center clinic (clinic cases), and the Religious Orders Study and the Rush Memory and Aging Project (ROS/MAP study subjects)

\begin{tabular}{lcc}
\hline & Probable AD & Possible AD \\
\hline Clinic cases & & \\
Number & $306(85.0)$ & $54(15.0)$ \\
Mean age at death \pm SD, years & $79.2 \pm 9.6$ & $80.7 \pm 6.6$ \\
Male & $107(35.0)$ & $25(46.3)$ \\
Non-hispanic white & $279(91.2)$ & $49(90.7)$ \\
Mean education \pm SD, years & $12.7 \pm 3.3$ & $13.8 \pm 3.7$ \\
Mean MMSE proximate to death \pm SD & $4.6 \pm 7.0$ & $5.7 \pm 7.3$ \\
\hline ROS/MAP study subjects & & \\
Number & $141(79.2)$ & $37(20.8)$ \\
Mean age at death \pm SD, years & $89.5 \pm 5.4$ & $87.3 \pm 6.5$ \\
Male & $57(40.4)$ & $17(46.0)$ \\
Non-hispanic white & $136(96.5)$ & $34(91.9)$ \\
Mean education \pm SD, years & $16.7 \pm 3.7$ & $16.6 \pm 3.2$ \\
Mean MMSE proximate to death \pm SD & $14.4 \pm 8.7$ & $13.4 \pm 8.8$ \\
\hline
\end{tabular}

The figures in parentheses represent the percentage.
Table 2. Relation between the clinical diagnosis of probable AD and possible $\mathrm{AD}$ with pathologic diagnoses of $\mathrm{AD}$ (by CERAD and NIA-Reagan criteria), chronic macroscopic cerebral infarctions and Lewy body disease for autopsied participants from the Rush Alzheimer's Disease Center clinic (clinic cases)

\begin{tabular}{lcc}
\hline Pathologic diagnoses & Probable AD & Possible AD \\
\hline CERAD & & \\
$\quad$ Definite AD & $244(79.7)$ & $41(75.9)$ \\
$\quad$ Probable AD & $42(13.7)$ & $10(18.5)$ \\
$\quad$ Possible AD & $4(1.3)$ & $1(1.9)$ \\
$\quad$ No AD & $16(5.2)$ & $2(3.7)$ \\
NIA-Reagan & & \\
$\quad$ High likelihood & $221(72.2)$ & $32(59.3)$ \\
$\quad$ Intermediate likelihood & $65(21.2)$ & $16(29.6)$ \\
$\quad$ Low likelihood & $13(4.4)$ & $5(9.3)$ \\
$\quad$ No AD & $7(2.3)$ & $1(1.9)$ \\
Cerebral infarctions & & \\
$\quad$ Not present & $262(85.6)$ & $38(70.4)$ \\
$\quad$ Present & $44(14.4)$ & $6(29.6)$ \\
Lewy body disease & & \\
$\quad$ Not present & $205(76.2)$ & $26(54.2)$ \\
$\quad$ Present & $64(23.8)$ & $22(45.8)$ \\
\hline
\end{tabular}

The figures in parentheses represent the percentage.

${ }^{1} 37$ probable AD and 6 possible AD cases missing Lewy body disease diagnoses. (table 2). Nearly $90 \%$ also met NIA-Reagan criteria for intermediate or high likelihood of pathologic AD. Persons with clinically possible AD were more likely to have a coexisting condition. One or more cerebral infarcts were present in nearly $30 \%$, and almost half had Lewy bodies.

\section{Relation of Clinical Diagnoses of AD to Pathologic \\ Diagnoses in Study Subjects}

Of 141 study subjects with clinically probable AD, 130 (92.2\%) met CERAD pathologic criteria for definite or probable AD (table 3). Similarly, more than $90 \%$ met intermediate or high likelihood of AD by NIA-Reagan pathologic criteria. In addition, more than a third had 1 or more chronic macroscopic cerebral infarctions, and nearly a quarter had nigral, limbic or neocortical Lewy bodies. Of 37 study subjects with clinically possible AD, $26(70.3 \%)$ met CERAD pathologic criteria for definite or probable $\mathrm{AD}$ (table 3 ). More than $70 \%$ met intermediate or high likelihood of AD by NIA-Reagan pathologic criteria. Persons with clinically possible AD were more likely to have a coexisting condition. One or more cerebral infarcts were present in more than $60 \%$, and more than a quarter had Lewy bodies.

Decision Rules Guiding the Clinical Diagnosis of Alzheimer's Disease
Table 3. Relation between the clinical diagnosis of probable AD and possible $\mathrm{AD}$ with pathologic diagnoses of $\mathrm{AD}$ (by CERAD and NIA-Reagan criteria), chronic macroscopic cerebral infarctions and Lewy body disease for autopsied participants from the Religious Orders Study and Rush Memory and Aging Project (ROS/MAP study subjects)

\begin{tabular}{lcr}
\hline Pathologic diagnoses & Probable AD & Possible AD \\
\hline CERAD & & \\
$\quad$ Definite AD & $78(55.3)$ & $10(27.0)$ \\
$\quad$ Probable AD & $52(36.9)$ & $16(43.2)$ \\
$\quad$ Possible AD & $5(3.6)$ & $5(13.5)$ \\
$\quad$ No AD & $6(4.3)$ & $6(16.2)$ \\
NIA-Reagan & & \\
$\quad$ High likelihood & $59(41.8)$ & $7(18.9)$ \\
$\quad$ Intermediate likelihood & $69(48.9)$ & $16(43.2)$ \\
$\quad$ Low likelihood & $13(9.3)$ & $14(37.8)$ \\
$\quad$ No AD & $0(0)$ & $0(0)$ \\
Cerebral infarctions & & \\
$\quad$ Not present & $87(61.7)$ & $14(37.8)$ \\
$\quad$ Present & $54(38.3)$ & $22(62.2)$ \\
Lewy body disease & & \\
$\quad$ Not present & $106(75.2)$ & $27(73.0)$ \\
$\quad$ Present & $35(24.8)$ & $10(27.0)$ \\
\hline
\end{tabular}

The figures in parentheses represent the percentage. 


\section{Discussion}

Most studies of the relation between the clinical and pathologic diagnosis of $\mathrm{AD}$ are from specialty dementia clinics following an evaluation that includes an interview with a knowledgeable informant, neuroimaging and blood work, and multi-disciplinary case conferencing. In these settings, pathologic confirmation of the diagnosis of clinically probable AD typically exceeds $80 \%$ and can approach $100 \%$ when restricted to typical $\mathrm{AD}$ [37-41]. In general, pathologic confirmation of the diagnosis of possible $\mathrm{AD}$ is somewhat lower, ranging from about 65 to $85 \%$ in clinic settings. Of the more than 300 patients with clinically probable AD in this study, the diagnosis was confirmed by neuropathology in more than $90 \%$. Likewise, about $90 \%$ of the more than 50 patients with clinically possible $\mathrm{AD}$ also met neuropathologic criteria for $\mathrm{AD}$. These data suggest that the procedures used in the Rush Alzheimer's Disease Center clinic are comparable to those used at other tertiary-care dementia specialty centers.

There have been fewer reports of the relation between the clinical and pathologic diagnosis of $\mathrm{AD}$ in community-based studies. In general, the rates have been lower, ranging from 65 to $85 \%$ for clinically probable $\mathrm{AD}$ and 35 to $70 \%$ for clinically possible AD [42-46]. The lower rates in these studies likely result from several factors. First, in contrast to clinic-based samples [47], persons in community-based studies are often not recognized by family members [48] or community physicians [49] as having cognitive difficulties. Second, in longitudinal, community-based studies, the diagnosis of AD is often made at a time when cognitive impairment is mild and the presence of dementia unclear. In other words, in the community, the differential diagnosis is about both the presence of dementia and its cause, compared to the clinic, where dementia is typically obvious and the differential only about its cause. Third, many clinical-pathologic studies in clinic-based settings are restricted to more typical cases of $\mathrm{AD}$, which may inflate correlations in such studies. By contrast, the study subjects are often considerably older, which likely increases the prior probability of $\mathrm{AD}$ in such studies.

We developed a system of decision rules to guide the clinical diagnosis of $\mathrm{AD}$ in two large community-based studies. The procedures were implemented in a time-efficient manner by neurologists, geriatricians and geriatric nurse practitioners. It did not require an interview with an informant, neuroimaging or blood work. Of more than 140 study subjects with clinically probable $A D$, the diagnosis was confirmed by neuropathology in more than $90 \%$. For the 37 study subjects with clinically possible $\mathrm{AD}, 60-70 \%$ met neuropathologic criteria for AD. Consistent with other community-based studies [42], more than a third of the study subjects with probable AD and more than $60 \%$ of those with possible AD had cerebral infarctions at autopsy. This suggests that MRI would likely have increased the detection of cerebrovascular disease and potentially increased the number of cases of vascular dementia [50]. Further, studies that focus on causes of dementia other than $\mathrm{AD}$ (e.g. vascular cognitive impairment, frontotemporal dementia) would likely benefit from ancillary tests such as structural or functional neuroimaging.

The pathologic diagnosis of AD was based only on the degree of $A D$ pathology, even if other pathologic changes were present. The most common coexisting pathology was cerebral infarctions. These were much more common in study subjects than in clinic patients and more common in possible $\mathrm{AD}$ than probable $\mathrm{AD}$ for both groups. Although there are no accepted criteria for the pathologic diagnosis of vascular dementia [51-53], it is now accepted that these 2 lesions commonly coexist and add to or interact with one another to cause dementia [42, 54-56]. These data suggest that the presence of infarctions reduces the amount of $\mathrm{AD}$ pathology needed to cause cognitive impairment and may account in part for a greater number of persons with possible $\mathrm{AD}$ having intermediate amounts of AD pathology.

$\mathrm{AD}$ is a complex function of numerous genetic and environmental risk factors that cause or interact with a variety of pathologic, biochemical and molecular changes in the brain. Understanding this complex disease will increasingly requirelarge, longitudinal, multidisciplinary studies that can simultaneously address the myriad factors involved in its occurrence. These studies will be time-consuming and expensive. The present data provide support for the use of clinical prediction rules to guide clinical judgment in these studies.

\section{Acknowledgments}

We thank the patients and families of the Rush Alzheimer's Disease Center, the nuns, priests and brothers from across the country participating in the Religious Orders Study and the older persons from across northeastern Illinois participating in the Rush Memory and Aging Project. We thank the staff of the Rush Alzheimer's Disease Center and the Rush Institute for Healthy Aging.

This study was supported by NIA grants P30AG10161, R01AG15819 and R01AG17917. 


\section{References}

1 Bennett DA, Schneider JA, Arvanitakis Z, et al: Neuropathology of older persons without cognitive impairment from two communitybased studies. Neurology 2006;66:18371844.

-2 Bennett DA, Schneider JA, Buchman AS, Mendes de Leon CF, Bienias JL, Wilson RS: The Rush Memory and Aging Project: Study design and baseline characteristics of the study cohort. Neuroepidemiology 2005;25: 163-175.

-3 Katzman R, Terry R, DeTeresa R, et al: Clinical, pathological, and neurochemical changes in dementia: a subgroup with preserved mental status and numerous neocortical plaques. Ann Neurol 1988;23:138-144.

$\checkmark 4$ Hulette CM, Welsh-Bohmer KA, Murray MG, Saunders AM, Mash DC, McIntyre LM: Neuropathological and neuropsychological changes in 'normal' aging: evidence for preclinical Alzheimer disease in cognitively normal individuals. J Neuropathol Exp Neurol 1998;57:1168-1174.

5 Knopman DS, Parisi JE, Salviati A, et al: Neuropathology of cognitively normal elderly. J Neuropathol Exp Neurol 2003;62: 1087-1095.

-6 Schmitt FA, Davis DG, Wekstein DR, Smith CD, Ashford JW, Markesbery WR: 'Preclinical' AD revisited: neuropathology of cognitively normal older adults. Neurology 2000; 55:370-376.

7 Galvin JE, Powlishta KK, Wilkins K, et al: Predictors of preclinical Alzheimer disease and dementia: a clinicopathologic study. Arch Neurol 2005;62:758-765.

$>8$ Wilson RS, Gilley DW, Bennett DA, Hebert LE, Beckett LA, Evans DA: Person-specific paths of cognitive decline in Alzheimer's disease and their relation to age. Psychol Aging 2000;15:18-28.

$>9$ Hui JS, Wilson RS, Bennett DA, Bienias JL, Gilley DW, Evans DA: Rate of cognitive decline and mortality in Alzheimer's disease. Neurology 2003;61:1356-1361.

10 Barnes LL, Wilson RS, Li Y, Gilley DW, Bennett DA, Evans DA: Change in cognitive function in Alzheimer's disease in AfricanAmerican and white persons. Neuroepidemiology 2005;25:16-22.

11 Morris JC, Heyman A, Mohs RC, et al: The consortium to establish a registry for $\mathrm{Alz}$ heimer's disease (CERAD). I. Clinical and neuropsychological assessment of Alzheimer's disease. Neurology 1989;39:11591165.

-12 Knopman DS, DeKosky ST, Cummings JL, et al: Practice parameter: diagnosis of dementia (an evidence-based review). Report of the Quality Standards Subcommittee of the American Academy of Neurology. Neurology 2001;56:1143-1153.
13 McKhann G, Drachmann D, Folstein M, Katzman R, Price D, Stadlan E: Clinical diagnosis of Alzheimer's disease. Report of the NINCDS-ADRDA Work Group under the auspices of Department of Health and Human Services Task Force on Alzheimer's Disease. Neurology 1984;34:939.

14 Roman GC, Tatemichi TK, Erkinjuntti T, et al: Vascular dementia: diagnostic criteria for research studies. Report of the NINDS-AIREN International Workshop. Neurology 1993;43:250-260.

15 Langston JW, Widner H, Goetz CGT, et al: Core Assessment Program for Intracerebral Transplantations (CAPIT). Mov Disord 1992;7:2-13.

16 Hamilton, M: A rating scale for depression. J Neurol Neurosurg Psychiatry 1960;23:5662.

17 Robins LN, Helzer JE, Ratcliff KS, Seyfried W: Validity of the Diagnostic Interview Schedule. II. DSM-III diagnoses. Psychol Med 1982;12:855-870.

18 Bennett DA, Shannon KM, Beckett LA, Goetz CG, Wilson RS: Metric properties of nurses' ratings of parkinsonian signs with a modified Unified Parkinson's Disease Rat-

ing Scale. Neurology 1997;49:1580-1587.
19 Wilson RS, Beckett LA, Barnes LL, et al: Individual differences in rates of change in cognitive abilities of older persons. Psychol Aging 2002;17:179-193.

20 Wilson RS, Bennett DA: Assessment of cognitive decline in old age with brief tests amenable to telephone administration. Neuroepidemiology 2005;25:19-25.

21 Wasson JH, Sox HC, Neff RK, Goldman L: Clinical prediction rules: applications and methodological standards. N Engl J Med 1985;313:793-799.

22 Laupacis A, Sekar N, Stiell IG: Clinical prediction rules: a review and suggested modifications of methodological standards. JAMA 1997;277:488-494.

23 Reilly BM, Evans AT: Translating clinical research into clinical practice: impact of using prediction rules to make decisions. Ann Intern Med 2006;144:201-209.

24 Bennett DA, Wilson RS, Schneider JA, et al: Natural history of mild cognitive impairment in older persons. Neurology 2002;59: 198-205.

25 Boyle PA, Wilson RS, Aggarwal NT, Tang Y, Bennett DA: Mild cognitive impairment: risk of Alzheimer disease and rate of cognitive decline. Neurology 2006;67:441-445.

26 Petersen RC, Parisi JE, Dickson DW, et al: Neuropathologic features of amnestic mild cognitive impairment. Arch Neurol 2006;63: 665-672.

27 Barnes LL, Schneider JA, Boyle PA, Bienias JL, Bennett DA: Memory complaints are related to Alzheimer disease pathology in older persons. Neurology, in press.
-28 Petersen RC: Mild cognitive impairment: where are we? Alzheimer Dis Assoc Disord 2005;19:166-169.

29 Bennett DA, Schneider JA, Bienias JL, Evans DA, Wilson RS: Mild cognitive impairment is related to Alzheimer disease pathology and cerebral infarctions. Neurology 2005; 64:834-842.

30 Mirra SS, Heyman A, McKeel D, et al: The Consortium to Establish a Registry for Alzheimer's Disease (CERAD). II. Standardization of the neuropathologic assessment of Alzheimer's disease. Neurology 1991;41: 479-486.

-31 Braak H, Braak E: Neuropathological stageing of Alzheimer-related changes. Acta Neuropathol (Berl) 1991;82:239-259.

32 Consensus recommendations for the postmortem diagnosis of Alzheimer's disease. The National Institute on Aging and Reagan Institute Working Group on Diagnostic Criteria for the Neuropathological Assessment of Alzheimer's Disease. Neurobiol Aging 1997;18(suppl 4):S1-S2.

33 Schneider JA, Bienias JL, Wilson RS, BerryKravis E, Evans DA, Bennett DA: Relation of the apolipoprotein E $\varepsilon 4$ allele to cerebral infarction in older persons. Stroke 2005;36: 954-959.

34 Schneider JA, Bienias J, Gilley DW, Kvarnberg D, Mufson EJ, Bennett DA: Improved detection of neurofibrillary pathology in Alzheimer's disease. J Histochem Cytochem 2002;50:99-106.

35 McKeith IG, Galasko D, Kosaka K, et al: Consensus guidelines for the clinical and pathologic diagnosis of dementia with Lewy bodies (DLB): report of the consortium on DLB international workshop. Neurology 1996;47:1113-1124.

36 Folstein MF, Folstein SE, McHugh PR: 'MiniMental State': a practical method for grading the mental state of patients for the clinician. J Psychiatr Res 1975;12:189-198.

37 Kukull WA, Larson EB, Reifler BV, Lampe TH, Yerby MS, Hughes JP: The validity of 3 clinical diagnostic criteria for Alzheimer's disease. Neurology 1990;40:1364-1369.

38 Galasko D, Hansen LA, Katzman R, et al: Clinical-neuropathological correlations in Alzheimer's disease and related dementias. Arch Neurol 1994;51:888-895.

39 Victoroff J, Mack WJ, Lyness SA, Chui HC: Multicenter clinicopathological correlation in dementia. Am J Psychiatry 1995; 152: 1476-1484.

40 Gearing M, Mirra SS, Hedreen JC, Sumi SM, Hansen LA, Heyman A: The Consortium to Establish a Registry for Alzheimer's Disease (CERAD). X. Neuropathology confirmation of the clinical diagnosis of Alzheimer's disease. Neurology 1995;45:461-466. 
-41 Morris JC, McKeel DW Jr, Fulling K, Torack RM, Berg L: Validation of clinical diagnostic criteria for Alzheimer's disease. Ann Neurol 1988;24:17-22.

-42 Neuropathology Group of the Medical Research Council Cognitive Function and Aging Study (MRC CFAS): Pathologic correlates of late-onset dementia in a multicentre, community-based population in England and Wales. Lancet 2001;357:169-175.

43 Plassman BL, Khachaturian AS, Townsend JJ, et al: Comparison of clinical and neuropathologic diagnoses of Alzheimer's disease in 3 epidemiologic samples. Alzheimer Dement 2006;2:2-11.

44 Lim A, Tsuang D, Kukull W, et al: Cliniconeuropathological correlation of Alzheimer's disease in a community-based case series. J Am Geriatr Soc 1999;47:564-569.

45 Massoud F, Devi G, Stern Y, et al: A clinicopathological comparison of communitybased and clinic-based cohorts of patients with dementia. Arch Neurol 1999;56:13681373.
46 Petrovitch H, White LR, Ross GW, et al: Accuracy of clinical criteria for AD in the Honolulu-Asia Aging Study, a population-based study. Neurology 2001;57:226-234.

47 Cacchione PZ, Powlishta KK, Grant EA, Buckles VD, Morris JC: Accuracy of collateral source reports in very mild to mild dementia of the Alzheimer type. J Am Geriatr Soc 2003;51:819-823.

-48 Ross GW, Abbott RD, Petrovitch H, et al: Frequency and characteristics of silent dementia among elderly Japanese-American men: the Honolulu-Asia Aging Study. JAMA 1997;277:800-805.

49 Ganguli M, Rodriguez E, Mulsant B, et al: Detection and management of cognitive impairment in primary care: the Steel Valley Seniors Survey. J Am Geriatr Soc 2004;52: 1668-1675.

50 Lopez OL, Kuller LH, Becker JT, et al: Classification of vascular dementia in the Cardiovascular Health Study Cognition Study. Neurology 2005;64:1539-1547.

51 Knopman DS, Parisi JE, Boeve BF, et al: Vascular dementia in a population-based autopsy study. Arch Neurol 2003;60:569-575.
52 Pantoni L, Sarti C, Alafuzoff I, et al: Postmortem examination of vascular lesions in cognitive impairment: a survey among neuropathological services. Stroke 2006;37: 1005-1009.

53 Vinters HV, Ellis WG, Zarow C, et al: Neuropathologic substrates of ischemic vascular dementia. J Neuropathol Exp Neurol 2000; 59:931-945.

54 Schneider JA, Wilson RS, Bienias JL, Evans DA, Bennett DA: Cerebral infarctions and the likelihood of dementia from Alzheimer's disease pathology. Neurology 2004;62:11481152.

55 Snowdon DA, Greiner LH, Mortimer JA, Riley KP, Greiner PA, Markesbery WR: Brain infarction and the clinical expression of Alzheimer disease: the Nun Study. JAMA 1997;277:813-817.

56 Petrovitch H, Ross GW, Steinhorn SC, et al: $\mathrm{AD}$ lesions and infarcts in demented and non-demented Japanese-American men. Ann Neurol 2005;57:98-103. 